\title{
Contrato versus caridad: una reconsideración de la relación entre ciudadanía civil y ciudadanía social ${ }^{*}$
}

\author{
NANCY FRASER y LINDA GORDON \\ NorthWestern University
}

En este trabajo se analiza la kmitologia cultural" que impregna la concepción de la ciudadanía civil en los Estados Unidos, la cual, para nuestras autoras, es una rémora en orden a que pueda aflorar un nuevo concepto de la «ciudadanía social». Para desbrozar el terreno, desde un punto de vista ideológico, en el que podrían emerger nuevas conceptualizaciones adecuadas para el ideal de la ciudadania social, Fraser y Gordon hacen una genealogía del modelo dicotómico que se ha impuesto en la modernidad sobre las relaciones humanas, y que consiste en la oposición contrato versus caridad. Sobre la noción de contrato se vertebra la concepción de la sociedad civil propia del llamado eindividualismo posesivom, y la noción contrapuesta de caridad se configura como propia de la kesfera familiar» y privada. Los referentes de género que corres- ponden respectivamente a estas nociones son lo masculino y lo femenino. Se constituye de este modo uuna tendencia cultural a centrarse en dos formas bastante extremas de relación humana: los intercambios contractuales de cosas fungibles equivalentes, por un lado, y la caridad unilateral, no recíproca, por otro». La pregnancia de esta oposición binaria es tal que el lenguaje político en que se legitiman las prestaciones sociales invoca uno u otro de los términos de la polaridad - jerarquizada a favor del contrato-: se trata, ora de "compensaciones al trabajador», ora de «asistencia públicas, con los perfiles de género respectivos de sus destinatarios, varones y mujeres. Mientras que "la ciudadanía social" apuntaria a formas diferentes de interacción más allá de estos sesgos ideológico-genéricos: solidaridad, interdependencia, etc.

"Ciudadano y "ciudadanía» son palabras llenas de significado. Hablan de respeto, de derechos, de dignidad. Piénsese en el sentido y la emoción que contenía el citoyen francés de 1789 , una palabra que condenaba la tiranía y la jerarquía social, a la vez que afirmaba la autonomía y la igualdad; en aquel momento, incluso las mujeres consiguieron el nombre de citoyenne, en vez de madame o mademoiselle. Desde entonces, la palabra aparece a menudo delante de otro término, añadiendo siempre dignidad a éste, como en "ciudadano soldado", "ciudadano trabajador", "ciudadana madre». Tiene tanta dignidad que rara vez aparece en el lenguaje coloquial.

* Traducción de Pedro Francés Gómez. 
En las pocas frases informales en que se emplea, se hace con un sentido de aprobación y respeto, como en "ciudadano del mundo" o "comité de ciudadanos». No se encuentran usos peyorativos. Es una palabra humanista importante, monumental.

Se dice que los americanos casi nunca hablan de "ciudadanía social». Si se usara, esa expresión sugeriría la idea de que en un estado del bienestar la ciudadanía implica el derecho a los bienes sociales. Extendería a los subsidios sociales la aureola de dignidad que rodea a "ciudadanía" y «derechos". Quienes disfrutaran de la "ciudadanía social» adquirirían «derechos sociales», no «limosnas». Esto no sólo significa que tendrían garantizada la ayuda suficiente para mantener su estatus como miembros de la sociedad con derecho a «igual respeto". También significa que compartirian un conjunto de instituciones y servicios comunes diseñados para todos los ciudadanos, cuyo uso constituiría la práctica de la ciudadanía social: por ejemplo, escuelas y parques públicos, seguridad social universal o servicios públicos de salud. Así, la expresión "ciudadanía social» evoca aspectos de las tres grandes tradiciones de la teoría política: las preocupaciones liberales en torno a los derechos (sociales) y al respeto; las normas comunitarias de solidaridad y responsabilidad compartida; y los ideales republicanos de participación en la vida pública (a través del uso de los «bienes y servicios públicos»).

Pero la expresión "ciudadanía social" casi nunca se oye en el debate público estadounidense actual. Aquí, los bienes sociales quedan totalmente fucra de la aureola de dignidad que rodea a la «ciudadanía». Ser receptor de "subsidios" se considera razón para la falta de respeto, una amenaza para la ciudadanía, más que su realización. Y en el campo de los servicios sociales, la palabra "público» es, a menudo, peyorativa. Los hospitales públicos son instituciones de último recurso, no son lugares para la solidaridad, sino para el estigma. Las escuelas públicas, consideradas en un tiempo las "cunas de la ciudadanía", son a menudo tan inferiores a las privadas que encajan en el patrón general de uriqueza privada, miseria pública". Y los parques públicos son a menudo demasiado peligrosos como para entrar en ellos. En general, la idea de ciudadanía social en un estado del bienestar no está en la línea de las corrientes más importantes de la cultura política americana contemporánea. Las connotaciones de la ciudadanía son tan positivas, fuertes y prestigiosas, mientras las del "bien social» son tan negativas, débiles y degradadas, que aquí "ciudadanía social» suena casi oxímoro.

Mientras la "ciudadanía social» señala una ausencia en el discurso político estadounidense, la ciudadanía civil enfatiza su presencia. Los americanos se vanaglorian de su compromiso con las libertades y derechos civiles, aunque no siempre los respeten en la práctica. Frases como ulibertades individuales» o «libertad de expresión» ocupan un lugar central en 
las tradiciones retóricas del país, a pesar de los frecuentes esfuerzos por restringirlas. Estos temas tienen tal resonancia y poder que, en ocasiones, algunos movimientos colectivos han tratado de aprovechar su prestigio para promover sus objetivos de igualdad social -por ejemplo, el «movimiento de los derechos civiles» en favor de la igualdad racial.

Así, la cultura política de los Estados Unidos combina un discurso sobre la "ciudadanía civil» ricamente elaborado con una casi total ausencia de discurso sobre la "ciudadanía social». En consecuencia, el pensamiento americano sobre los bienes sociales se ha configurado en su mayor parte a través de imágenes tomadas de la ciudadanía civil. El resultado -según defendemos más adelante- es una tendencia cultural a centrarse en dos formas bastante extremas de relación humana: los intercambios contractuales de cosas fungibles equivalentes, por un lado, y la caridad unilateral, no recíproca, por otro. Frente a esto, la "ciudadanía social» apunta hacia otro tipo de relación. Su ausencia en los Estados Unidos presagia $-\mathrm{y}$ fortalece - una supresión cultural de alternativas a la rígida oposición binaria, contrato versus caridad.

Por estas razones, la expresión "ciudadanía social» proporciona un punto de vista privilegiado para comprender, y criticar, la cultura política americana. Aunque no está exenta de dificultades. No sólo presupone la unidad, cada vez más problemática, de la nación-estado - una dificultad muy importante que no discutiremos aquí- sino que las concepciones habituales de la ciudadanía social están totalmente impregnadas por el androcentrismo y el etnocentrismo. Así que nuestra discusión procede simultáneamente en dos frentes. Empleamos un concepto derivado en su mayor parte de la teoría sociológica inglesa para criticar la cultura política americana, pero usamos al mismo tiempo aspectos de la historia y la cultura americanas para mostrar algunas limitaciones del concepto inglés.

Nuestra piedra de toque es el brillante ensayo de T.H. Marshall "Citizenship and Social Class» ("Ciudadanía y clase social"), publicado en 1949 y fuente de todas las discusiones sobre la "ciudadanía social». Marshall fue el primero en conceptualizar y defender la ciudadanía social como el punto culminante del desarrollo histónico de la ciudadanía moderna. En su concepción, era la última de tres fases. La primera, la ciudadanía civil, se habría construido principalmente en el siglo xvm y habría establecido los derechos necesarios para la libertad individual: los derechos a la propiedad y a la autonomía personal y, especialmente, el derecho al acceso a la justicia. La segunda fase, la ciudadanía política, se desarrollaría fundamentalmente en el siglo XIX y abarcaría - desde su punto de vista- el derecho a participar en el ejercicio del poder político, bien desempeñandolo directamente o bien a través del derecho al voto. La tercera y última fase, la ciudadanía social, se estaría construyendo en el siglo XX; según Marshall no sólo abarcaría el derecho a un mínimo de seguridad económica, sino 
que implicaría también un derecho, de mayor alcance, ua compartir todo el patrimonio social y a vivir la vida de un ser civilizado según los patrones que prevalezcan en la sociedads. ${ }^{1}$

Desde luego, Marshall escribía en un período de optimismo respecto a la ciudadanía social. Tras la segunda guerra mundial, el electorado británico derribó ucon desagradecimiento" a Churchill e instaló en el poder a un Partido Laborista que se había comprometido a construir un estado del bienestar. Marshall previó un estado que no sólo eliminaría las desigualdades más clamorosas producto de la sociedad de clases, sino que borraría realmente algunas diferencias de estatus basadas en la estructura de clases misma: Escribió en torno a la importancia que tendrían los bienes sociales para crear la igualdad de estatus y la solidaridad social: «Incluso aunque las subvenciones se paguen en efectivo, la fusión de clases adquiere la forma externa de una nueva experiencia común. Todos saben lo que significa tener una cartilla de la seguridad social [...] o recoger los subsidios a la infancia o las pensiones en la oficina de correos. Pero donde el beneficio toma la forma de un servicio, el elemento cualitativo (de experiencia compartida y estatus común) se incorpora al beneficio mismo y no sólo al proceso por el cual es obtenido. Por tanto, la extensión de tales servicios puede tener un profundo efecto sobre aspectos cualitativos de la diferenciación social».2 Marshall imaginó que los servicios universales de educación y salud, al desconectar progresivamente la renta real de la renta en dinero, ayudarian a disolver las diferentes culturas de clase en una «civilización unificada». Anticipó que el "patrón mínimo" establecido por los bienes sociales se elevaría alguna vez hasta aproximarse al máximo; de modo que los extras que los ricos podrían comprar serían simplemente objetos decorativos. Lo normal llegaría a ser el servicio público, en vez del privado.

El utopismo de Marshall no derivaba de una simple visión revolucionaria del progreso. Por el contrario, analizó las contradicciones entre las tres dimensiones de la ciudadanía desarrolladas y también las tensiones entre los ciudadanos. Reparó en aquellos que habían permanecido excluidos de la ciudadanía, y comprendió que la ciudadanía misma había funcionado como arquitecto de la desigualdad social. También afrontó el problema de si se podría alcanzar un estatus uniforme de ciudadanía respetando al mismo tiempo la inviolabilidad de las leyes del mercado y la propiedad privada. Su conclusión fue que el más amplio desarrollo de la ciudadanía social podría renovar las relaciones sociales en el sentido de hacerlas más igualitarias.

Resulta tonificante leer el ensayo de T.H. Marshall en este período de extendido pesimismo sobre la vida pública, pero no debemos asumirlo acríticamente. Cuando colocamos en el centro de nuestro interés cuestiones sobre el género y la raza, los elementos clave del análisis de Marshall 
se tornan problemáticos. Su periodización de las tres fases de la ciudadanía, por ejemplo, se adecua sólo a la experiencia de los hombres, trabajadores y blancos. Una minoría de la población. Sus distínciones conceptuales entre ciudadanía civil, política y social presuponen la jerarquía de género y de raza, en vez de problematizarla. Finalmente, su asunción, mantenida en la teoría y la práctica socialdemócrata posterior, de que el principal objetivo de la ciudadanía social es la eliminación de la desigualdad de clase y la protección de las fuerzas del mercado, desatiende otros ejes clave de desigualdad y otros mecanismos y ámbitos de dominación.

Sin embargo, para nuestros propósitos aquí, resulta más importante el optimismo de Marshall respecto a la facilidad con que la ciudadanía social podría construirse sobre la base establecida por los términos de la ciudadanía civil. Este optimismo parece fuera de lugar desde el punto de vista de los EE.UU. actuales, donde no sólo hallamos nuevos caminos para la miseria y la desigualdad, sino también nucvas cotas de hostilidad conservadora hacia el estado del bienestar. En este contexto del capitalismo en proceso de desindustrialización, se hace necesario reconsiderar si la mitología cultural que rodea a la ciudadanía civil obstaculiza la construcción de la ciudadanía social.

En lo que sigue reexaminaremos la relación entre ciudadanía civil y social. (Dejamos de lado las cuestiones sobre la relación entre ciudadanía política y social, aunque también sería interesante su reexamen a la luz de los problemas de género y de raza.) Nuestro interés es la construcción histórica de la oposición entre contrato y caridad. Seguiremos la genealogía de esta oposición desde sus orígenes en la mitología cultural de la ciudadanía civil hasta su papel actual, que consiste en bloquear el desarrollo de la ciudadanía social en los EE.UU. Al hacer esto, tratamos de incorporar la perspectiva de quienes fueron originariamente excluidos de la ciudadanía, sobre todo las mujeres blancas y las minorías de ambos sexos.

La primera "fase" de la ciudadanía según el análisis de Marshall -ciudadanía civil- no significó en absoluto un progreso para todos los afectados. Al contrario, en ocasiones, al elevarse el estatus de algunos, descendió el estatus relativo de otros; las convenciones que configuraron la ciudadanía civil contribuyeron a construir formas modernas de dominación masculina y supremacía blanca, así como de explotación de clase. Tampoco puede entenderse el desarrollo de la ciudadanía civil aislado del problema del derecho a la ayuda social. En todas las sociedades hay personas que no pueden procurarse la subsistencia por los medios socialmente aceptados, por ejemplo, los minusválidos o las personas que carecen de apoyo familiar. Los nuevos derechos individuales que surgieron con la ciudadanía 
civil recortaron frecuentemente el tradicional derecho a la ayuda de la comunidad que estas personas tenían. También fundaron una oposición ideológica, marcada por el género, entre contrato y caridad, que aún hoy estructura la aportación estatal de bienes sociales. ${ }^{3}$

En principio, "ciudadanía" significó, en inglés, el hecho de tener la residencia en una ciudad. Como los habitantes de las ciudades estuvieron entre los primeros grupos que se liberaron de las relaciones feudales de servidumbre, el término adquirió también connotaciones de libertad, Marshall situó la primera ciudadanía en sentido moderno en los inicios de la Inglaterra moderna, donde hacia finales del siglo XVII había sido legalmente abolida la servidumbre permanente y hereditaria. "Ciudadanía» se hizo en este momento sinónimo de un estatus libre, y los derechos inherentes a ese estatus se denominaron "cívicos" o «civiles". Incluían el derecho a la propiedad privada y a contratar válidamente, el derecho a acceder a los tribunales, la libertad personal y, después de la Revolución inglesa, la libertad de expresión, pensamiento y credo religioso.

Los británicos fueron pioneros en el desarrollo de un modelo de justificación de esta forma de ciudadanía de gran éxito, la teoría del contrato social. La variante liberal de esta teoria justificaba el gobierno constitucional moderno localizando el origen del poder político legítimo en un acuerdo voluntario y convencional entre «hombres» racionales libres en un «estado de naturaleza». El resultado de su "pacto originario" sería el gobierno de la ley y, simultáneamente, su otra cara: la constitución legal de una esfera "civil» dentro de la sociedad, en la que individuos independientes podrían contratar libremente unos con otros, seguros de sus personas y propiedades. Estos individuos adquirirían de ese modo personalidad legal y derechos civiles, se convertirían en «ciudadanos" de la "sociedad civil».

La constitución de la «sociedad civil», tanto en la teoría del contrato como en la legislación sobre contratos, significó una revolución en la ontología social. Los sujetos de la sociedad civil se concebían como windividuos» previos a sus relaciones. Las relaciones, en cambio, se establecieron como acuerdos voluntarios, temporales y limitados, concluidos a partir del interés individual de cada uno. La relación prototípica era el acuerdo contractual, que consistía en un intercambio de equivalentes. Esto presuponía la libertad e independencia de los contratantes, unos mecanismos neutrales que les hicieran cumplir sus acuerdos, y la propiedad individual de los objetos intercambiados, fueran mercancías, fuerza de trabajo u opiniones. Dicho con la memorable frase de C.B. Macpherson, la sociedad civil se asentaba en un "individualismo posesivo».4

$\mathrm{El}$ «individualismo posesivo» fue sobre todo la base del intercambio económico, pero su alcance conceptual fue más amplio. Estuvo en la base de toda la sociedad civil moderna, que no abarca sólo el mero comercio, aunque esté construida a su imagen. La capacidad para celebrar libremen- 
te pactos o relaciones de cualquier clase presuponía la libertad del dominio de un señor, condición que se expresó como «ser dueño de sí mismo». Luego los "individuos» no sólo eran propietarios de sus bienes tangibles, sino también de sus "personas». Así, la ciudadanía civil no sólo garantizaba los derechos económicos de la propiedad, incluyendo el derecho a vender la propia fuerza de trabajo, sino también el derecho a la libertad personal - prohibición de la persecución, detención y encarcelamiento infundados o arbitrarios; libertad de movimientos y derecho a la integridad física; libertad de expresión, opinión y creencias-y el derecho a recurrir a los tribunales legales para hacer cumplir todos los anteriores.

Aunque hoy día nos parezca de sentido común, la nueva ontología de la sociedad civil representó un cambio revolucionario respecto de las ideas anteriores sobre la personalidad y las relaciones sociales. La concepción legal anterior no reconocía «individuos" como portadores de derechos previos a (e independientes de) su lugar jerárquico. Ni concebia las relaciones sociales como acuerdos limitados y libremente elegidos entre partes con igual estatus. Por el contrario, los estatus, definidos relacionalmente, eran previos o simultáneos a los individuos y configuraban los derechos y obligaciones de éstos. Además las relaciones características eran ordenaciones cuasi permanentes, involuntarias y jerárquicas que obligaban a los subordinados a obedecer y a los superiores a protegerles. Esta ontología anterior reconocía señores y sujetados, pero no había lugar para los ciudadanos.

La construcción moderna de la ciudadanía civil presentó un desafío fundamental a la subjetividad tradicional, pero no la sustituyó totalmente. Al contrario, ni siquiera los exponentes primitivos más radicales de la «sociedad civil» imaginaron que ésta abarcara toda la sociedad, ni vieron a todos los seres humanos como «individuos». Las mujeres, por supuesto, fueron excluidas durante siglos de la ciudadanía civil ( $y$ política) independiente, y no habia acuerdo sobre qué grado de ciudadanía debía otorgarse a los pobres y siervos. En consecuencia, la sociedad civil no se vio sino como un sector dentro de la sociedad, en una relación compleja y simbiótica con otros.

Podemos ejemplificar las aparentes paradojas que surgen aquí considerando dos formas modernas de dominación, la protección marital y la esclavitud. En principio, parece que el hecho de que las mujeres casadas fueran subsumidas bajo la personalidad legal de sus maridos a través de la ficción legal de la protección, es una continuación de la subjetividad tradicional; parece que así lo vio T.H. Marshall. Pero una más acertada comprensión de la protección la sitúa como un fenómeno moderno que contribuyó a constituir la ciudadanía civil. La protección fue una etapa en el declinar del patriarcado. (Por patriarcado no sólo entendemos cierto tipo de relaciones entre hombres y mujeres, sino que nos referimos a sociedades articuladas por relaciones jerárquicas, en las que casi todos 
estaban subordinados a algún superior, fuera éste rey, noble, señor feudal, padre o marido.) Sin embargo, con la construcción de la sociedad civil moderna, los hombres casados que antes habían sido adependientes", dentro de unidades patriarcales mayores, pasan a ser "cabezas" de familia e «individuos». Ser cabeza de familia se convirtió en un estatus importante y prestigioso, que competía con la posición social, clase y propiedad privada como fuente de la ciudadanía civil. La protección, al asegurar una posición legal independiente a todos los varones (blancos) cabezas de familia, democratizó las relaciones y puso fin al patriarcado entre hombres adultos libres (e.d., en EE.UU., blancos), a quienes el matrimonio confirió "independencia" y todos los derechos civiles, aunque aún no electorales. Luego, en contra de la posición de Marshall, la exclusión de la ciudadanía civil de las mujeres casadas no era simplemente un vestigio arcaico que desaparecería gradualmente al evolucionar la ciudadanía. La subsunción de las mujeres bajo la protección fue la otra cara de la ciudadanía civil moderna, y el fundamento que la hizo posible. Ambos se definieron mutuamente.

Lo mismo se puede decir de las brutales formas de esclavitud que surgieron en el Nuevo Mundo a la par que la elaboración de la ciudadanía civil. En los EE.UU., por ejemplo, los derechos civiles más amplios del mundo para los hombres blancos coexistian con el sistema de esclavitud de hombres y mujeres negros más totalitario y vejatorio de la historia. El moderno concepto "científico» de "raza" justificaba la dominación de los negros en el mismo momento en que el discurso de la «ciudadanía» proclamaba la libertad como derecho natural del "hombre» desde su nacimiento. La pieza central de la ciudadanía civil en «la república blanca" era una concepción de los derechos como propiedad. En los estados esclavistas, los blancos libres eran "personas", mientras los esclavos negros eran "propiedad», y la ley garantizaba los derechos de propiedad de los primeros sobre los segundos. Una de las grandes ironías de la historia de la ciudadanía civil es que el objetivo de la primera ley americana sobre la propiedad de la mujer casada, aprobada en Mississippi en 1839, fue asegurar a las esposas derechos sobre los esclavos de sus maridos. ${ }^{5}$ Mientras, los derechos de ciudadanía de los asalariados blancos descansaban, en parte, en su capacidad para ganar dinero a partir de la propiedad de sus cuerpos y su fuerza de trabajo. Sin embargo, el estatus del «trabajo libre» halló su sentido y prestigio, en buena parte, por contraste con la degradada condición de los esclavos, que trabajaban pero no cobraban. ${ }^{6}$ Por tanto, también en este punto las ordenaciones tratadas por Marshall como excepciones periféricas contribuyeron a construir los significados más importantes de la ciudadanía civil.

La ciudadanía civil hizo de los derechos de propiedad el modelo para los demás derechos, estimulando a la gente a que tradujera todas sus pre- 
tensiones a derechos de propiedad. No sorprende, por tanto, que los excluidos de la ciudadanía civil fueran normalmente quienes carecian de propiedad, incluyendo tanto a aquellos que eran incapaces de obtener los recursos definidos como propiedad, como a quienes eran propiedad. Y a la inversa, ciertos derechos civiles tuvieron menor importancia para quienes carecian de propiedad. El derecho de los cabezas de familia a defenderse de los intrusos y del estado, por ejemplo, no beneficiaba normalmente a mujercs y esclavos; más bien les privaba de protección exterior frente a los abusos de sus señores. ${ }^{7}$

Luego, a pesar de la retórica de la teoría liberal del contrato, los derechos civiles no fueron, en principio, derechos de los «individuos». Por el contrario, fueron paradigmáticamente derechos de varones blancos, propietarios y cabezas de familia, basados en parte en la responsabilidad hacia sus «dependientes". De hecho, en ciertos aspectos, "tener dependientes" llegó a ser una cualificación para la ciudadanía civil completa. La subordinación legal de las esposas bajo la protección marital y la clasificación legal de los esclavos como propiedad, no son simples exclusiones; son hechos que contribuyeron realmente a definir la ciudadanía civil, porque fue protegiendo, subordinando e incluso poseyendo a otros como los varones blancos, propietarios y cabezas de familia se convirtieron en ciudadanos.

Por tanto, no se puede decir que Marshall acierte al considerar la construcción de la ciudadanía civil simplemente como una elevación del estatus de aquellos hombres a quienes liberó de los vínculos de la dependencia. También representó una degradación comparativa del estatus de aquellas mujeres, hombres y niños que no adquirieron entonces personalidad legal independiente. Anteriormente, carecer de «independencia» civil había sido la condición normal de la mayoría; no suponía una degradación especial. Pero cuando los hombres blancos casados, pequeños terratenientes y cabezas de familia lograron un estatus legal independiente, el estar subsumido en la personalidad legal de otro se fue haciendo cada vez más anómalo -y degradante. Hacia la mitad del siglo xxx la protección y la esclavitud habían llegado a parecer aborrecibles a mucha gente. Algunas mujeres blancas y esclavos negros respondieron apropiándose la retórica del contrato social y reclamaron ser uindividuos», Pero, en contra del pensamiento de Marshall, no estaban pidiendo simplemente ser admitidos en un estatus preexistente; sino desafiando todo el orden social, ya que reclamaban los recursos sociales que permitían la eindependencia" de los varones blancos.

La construcción de la ciudadanía civil moderna había transformado también el fundamento de los derechos a los recursos sociales y tuvo, así, implicaciones respecto de la «distribución del bienestar social». En las sociedades precapitalistas tradicionales muchos derechos sobre los recursos 
sociales se basaban en alguna variante de la «economía moral», que limitaba el egoísmo individual. La propiedad privada era menos absoluta ya que estaba normalmente dividida, superponiéndose diversos derechos de uso. En consecuencia, gran parte de la propiedad no era completamente líquida, su disposición estaba restringida por la tradición. Los supuestos económico-morales restringían también las condiciones del arrendamiento de trabajo, alejándolo bastante del intercambio "libre» del mercado. La remuneración del trabajo, su contenido, quién lo realizaba y cuándo, todo estaba rodeado por una tradición que obligaba a todas las partes a aceptar las condiciones establecidas.

En este contexto, los derechos sobre los recursos sociales se basaban en diversas relaciones, y muchas obligaciones de prestar alimentos y apoyo derivaban de lazos familiares. La familia tradicional extensa abarcaba un conjunto de relaciones según el cual un amplio número de parientes y, a veces, vecinos y paisanos, tenían ciertas responsabilidades económicas unos para con otros. No había una única relación que definiera todo el derecho de alguien a ser mantenido, ya que las relaciones particulares se solapaban unas con otras para formar largas cadenas de dependencia y extensas redes de responsabilidad. Aunque estas relaciones eran privadas, diferian profundamente de la protección. Las mujeres ocupaban un lugar tan central como los hombres, aunque sin tanto poder, en el ámbito de las relaciones familiares. En vez de depender exclusivamente de sus maridos, las esposas tenían normalmente varias bases distintas sobre las que reclamar los recursos que necesitaran.

El surgimiento de la ciudadanía civil eliminó en parte este orden porque creó una forma nueva de derecho de propiedad que triunfó sobre las obligaciones y derechos tradicionales. Cuando la tierra se transformó en una mercancía, las poblaciones rurales perdieron sus derechos consuetudinarios de uso y sus aparcerías. Después, las "reformas" de la beneficencia tradicional debilitaron los antiguos derechos a la ayuda de la comunidad, facilitando la creación de un mercado de trabajo «libre" - libre de las obligaciones económico-morales de pagar una remuneración justa. En consecuencia, para la mayoría, el derecho de propiedad derivado de la ciudadanía civil significó la desposesión.

T.H. Marshall tenía en mente precisamente estas nuevas formas de propiedad y contrato de trabajo cuando afirmaba que el nacimiento de la ciudadanía civil obstaculizó, en principio, a la ciudadanía social, porque produjo un impacto negativo en el bienestar de muchos. Pero no percibió los sesgos familiar y de género que tuvo la ciudadanía civil, que también estaban preñados de presagios respecto del bienestar. La construcción del derecho de los hombres blancos a ser ciudadanos cabezas de familia creo simultáneamente una "dependencia» única de las mujeres respecto de sus maridos. Así, la ciudadanía civil contribuyó a crear la norma del salario 
familiar y cercenó los anteriores derechos sobre los recursos sociales basados en el parentesco. ${ }^{8}$

Estas ordenaciones señalaron la contracción de la familia a una «esfera» de la sociedad, contrapunto, y soporte, de la «sociedad civil». Mientras antes todas las relaciones sociales se habían configurado a partir del modelo del parentesco, la familia se convierte ahora en un campo social más, y su sentido cultural se ve alterado. ${ }^{9}$ A partir del siglo XVII la "esfera famihiar» se definió principalmente como el reino de "lo femenino" y «lo doméstico", una "esfera privada" de intimidad familiar y afecto. El resultado fue la aparición -especialmente entre la burguesía urbana y entre quienes aspiraban a un estatus de "clase media»- de una nueva disyunción ideológica entre dos clases de derechos a los recursos sociales, relacionados con las dos «esferas" de la sociedad. En la sociedad civil, "la esfera masculina», las relaciones parecían estar organizadas a través del contrato; los recursos se intercambiaban por sus equivalentes exactos en transacciones discretas, monetarizadas, entre individuos egoístas independientes. En la esfera doméstica de la familia íntima, por el contrario, los recursos más abundantes parecían ser los sentimientos, que quedaban totalmente fuera del circuito del intercambio.

Esta diferenciación de las dos esferas era ideológica en varios sentidos. Las normas que ella establecía eran violadas constantemente en la práctica, y también apropiadas y reconstruidas por distintos grupos sociales con diferentes intereses y objetivos. Por ejemplo, los hombres y mujeres de clase trabajadora utilizaron las ideas de la «domesticidad" de las mujeres para ayudar en su lucha en favor de unas mejores condiciones de vida y trabajo y para desarrollar sus propias nociones de disciplina y respetabilidad de la clase trabajadora. De igual modo, las activistas que luchaban en favor de los derechos de las mujeres utilizaron las ideas de domesticidad para afirmar la importancia de la influencia de las mujeres como madres.

La diferenciación entre las dos "esferas» era ideológica también en el sentido de que el lado "masculino" servía para definir los principios económicos y políticos fundamentales. El intercambio contractual, principio de la sociedad civil, llegó a ser hegemónico y, a pesar de la permanente e indispensable presencia de otros tipos de relaciones, representó cada vez más, para la cultura académica y la no académica, la forma básica de interacción humana. Muchas transacciones no comerciales se explicaron en estos términos, ya que el contrato funcionaba como metáfora del supuesto de elección racional en que el motivo fuera el propio beneficio. Por ejemplo, el mismo motivo que supuestamente definía el comportamiento de los consumidores y comerciantes se aplicó para explicar las relaciones políticas. Y fue la metáfora del contrato la que transformó el antiguo sentido del arrendamiento de trabajo en "trabajo asalariado", un intercambio 
contractual de fuerza de trabajo por salarios, supuestamente libre e igual. Esta universalización creciente del modelo del contrato influyó en sentido contrario sobre lo que representaba la "esfera femenina", haciendo aparecer la familia y las relaciones privadas como "naturales", fuera, por tanto, de la provincia de la teoría social.

Mientras el contrato parecía extender su influencia sobre una porcion cada vez mayor de relaciones humanas, el campo de sus alternativas parecía estrecharse. Las formas no contractuales de reciprocidad se asimilaron progresivamente al intercambio contractual, excepto aquellas que se desarrollaban "dentro" de la familia nuclear. Cualquier interacción que no apareciera como contractual ni familiar se concebía ahora como unilateral y enteramente voluntaria, sin comportar derecho ni responsabilidad alguna. Así, la hegemonía del contrato contribuyó a generar una concepción específicamente moderna de la "caridad" como alternativa complementaria al mismo. Según esta concepción, la caridad aparece como un donativo puro, unilateral, al que el receptor no tiene ningún derecho y al que el donante no está obligado. ${ }^{10}$ Asi, mientras el contrato tenía connotaciones tales como intercambio igual, beneficio mutuo, egoísmo, racionalidad y masculinidad, la caridad adquirió, por contraposición, las de desigualdad, donación unilateral, altruismo, sentimiento y, a veces, feminidad. Además, esta contraposición adoptó la forma de una oposición binaria estable que agotaba todas las posibilidades concebibles.

La oposición binaria entre contrato y caridad tendría consecuencias ideológicas aún mayores. En primer lugar, según la concepción moderna de la caridad, el donante adquiere buena reputación moral, mientras el receptor queda crecientemente estigmatizado. Sin embargo, tal distribución del valor había de ser inherentemente inestable, desde el momento en que la estigmatización de los receptores sembraba naturalmente dudas sobre los méritos de la donación. Al menos desde el siglo XIX, estas dudas dieron lugar a repetidas oleadas de "reforma" que trataban de contrarrestar los efectos «degeneradores» de las «donaciones indiscriminadas», tanto sobre los receptores como sobre la sociedad como un todo. De este modo, el contrato amenazó repetidamente a la caridad, y lo que parecía ser una oposición estable estuvo siempre en peligro de disolverse por la deslegitimación del principio más débil.

En segundo lugar, dado que la dicotomía contrato/caridad parecía negar la posibilidad de reciprocidad no contractual, impidió la existencia de todo un campo de prácticas populares que desafiaban la categorización binaria oficial. No sólo el parentesco, sino las obligaciones de buena vecindad y comunitarias siguieron siendo fuertes a pesar de la ideología de la familia nuclear independiente; y el soconro mutuo informal persistió bajo diversos aspectos y formas. Sin embargo, estas prácticas perdieron reconocimiento público y legitimación política oficial. Pasando el tiempo, la ca- 
rencia de un lenguaje que validara su existencia contribuyó a su disminución y decadencia. Además, a lo largo de todo el siglo XIX, mientras la caridad era constantemente atacada, la definición de la familia se hizo más nuclear. Las responsabilidades económicas respecto de los miembros de la familia extensa se debilitaron en los EE.UU., limitando así, aún más, la experiencia de una ayuda interpersonal al margen del contrato y la caridad.

De este modo, la imagen de la dicotomía contrato-versus-caridad hacía de nuevo realidad, en alguna medida, la exclusión de otros tipos de relaciones. Imprimía profundamente su sello sobre la aportación estatal de bienes públicos, que se desarrollaba según líneas dicotómicas. En los Estados Unidos, los programas gubernamentales se han dividido, desde comienzos del siglo XX, en dos corrientes. Los que tienen mayor legitimación, que han tomado parte de las formas del intercambio civil, tienden a garantizar derechos a la seguridad para algunos ciudadanos simulando contratos privados. Otros, por el contrario, se establecen como ofertas norecíprocas de ayuda a los pobres «honestos" y "necesitados»; en ellos el estado asume el papel de la caridad privada anterior. Estas dos corrientes han estado fuertemente marcadas por el género. La línea del contrato tuvo su primer prototipo americano en la "compensación del trabajador» (seguro de accidentes de trabajo), mientras que la línea de la caridad se plasmó en las "pensiones de viudedad"."

La dicotomía contrato/caridad, codificada en términos de género, persiste hoy en muchos países en la oposición entre programas de «seguridad social» y de "asistencia pública». Los primeros fueron diseñados por los reformadores de modo que aparecieran como "contributivos", incorporando, aparentemente, el principio del intercambio; de modo que los receptores para los que estos programas se pensaron, que debían ser miembros de la clase trabajadora, varones y relativamente privilegiados, se definen como «titulares». ${ }^{12}$ Mientras, la asistencia pública fue continuadora de la tradición "no-contributiva" de la caridad, de modo que sus receptores parecen obtener algo por nada, y quedan fuera de las normas contractuales.

Esta es, al menos, la visión oficial; pero la realidad es bastante más complicada. Muchos defensores de la seguridad social de comienzos del siglo XX empleaban a sabiendas el término "contributivo" como recurso retórico publicitario en favor de los nuevos programas, aunque sabían perfectamente que todos los programas sociales se financian mediante contribuciones, y sólo se diferencian en dónde y cómo se recaudan éstas (impuestos sobre las ventas, deducciones sobre el salario, etc.). Además, a pesar de su imagen oficial contractual, los programas aseguradores de la Seguridad Social de los Estados Unidos se desvían ostensiblemente de los principios actuariales, $y$ los beneficios no reflejan realmente las contribu- 
ciones financieras. Por otro lado, si se dice que la legitimación de las pensiones de jubilación de la Seguridad Social se basa en parte en la idea de que compensan un servicio anterior, se podría decir, con igual plausibilidad, que los programas aparentemente uno-contributivos», como la Ayuda a Familias con Hijos Dependientes (AFHD, sucesora de las pensiones por maternidad), compensan el "servicio" de las madres solteras al cuidar a sus hijos..$^{13}$ En cualquier caso, la dicotomía contrato versus caridad es menos una imagen real de los dos niveles del estado previsor americano que una ideología sobre su distinta legitimidad, basada en el privilegio del trabajo asalariado y en el desprestigio del trabajo no-retribuido de las mujeres. ${ }^{14}$

La mitología cultural de la ciudadanía civil afectó al diseño de los programas del estado del bienestar, pero también a la inversa, la construcción estratificada, generizada de los subsidios sociales ha afectado a las condiciones de la ciudadanía civil. Los subsidios sociales implican, a menudo, restricciones de los derechos civiles para sus receptores. Por cjemplo, a las demandantes de AFHD se las ha privado en los Estados Unidos del derecho a desplazarse fuera de su estado (derecho recortado por el requisito de la residencia en el propio estado); del derecho al proceso debido (recortado por los procedimientos administrativos que determinan la concesión y terminación de los beneficios); del derecho a la intimidad (recortado por los «exámenes de moralidad»); y del derecho a igual protección (recortado por todo lo anterior). Por el contrario, los beneficiarios de la «seguridad social» no sufren una pérdida semejante de derechos civiles.

Significativamente, los argumentos legales dirigidos a asegurar los derechos civiles de los beneficiarios, trataron de establecer, hacia los años sesenta y setenta, que las subvenciones sociales no eran "gratuitas", 0 "caritativas", sino que constituían una forma de "propiedad». Estos argumentos se diseñaron para adecuarse a la interpretación vigente de la regla del proceso debido que aparece en la Constitución de los Estados Unidos, según la cual, su protección se aplica sólo a las privaciones de propiedad. ${ }^{15}$ La dicotomía contrato/caridad aparece clara en esta interpretación y los argumentos que la rodean. Sólo recategorizando la asistencia pública como propiedad y recalificando a los beneficiarios como contratantes independientes pudieron mantenerse sus derechos civiles. Sin embargo, tal como algunos promotores de los derechos sociales advirtieron entonces, estos términos no eran los adecuados para expresar una visión de todo el contenido de la ciudadanía social. Los argumentos que partían de la identificación del bienestar con la propiedad ofrecian algunas ventajas procesales, pero no establecieron un derecho sustantivo a la seguridad económica a través de una ayuda estatal adecuada. Aunque los beneficiarios de la asistencia pública recuperaron el derecho al proceso debido, no se les re- 
conoció ningún derecho a ser sacados de la pobreza. Tuvieron que olvidar cualquier posibilidad de un derecho «a compartir todo el patrimonio social y a vivir la vida de un ser civilizado según los patrones que prevalezcan en la sociedads.16

En la dicotomía contrato-versus-caridad, el contrato es el polo más potente. Es comprensible, por tanto, que los reformadores que intentaban ampliar los derechos sociales trataran de llevar el "bienestar" del lado de la caridad al de la propiedad. Lograron adaptar el lenguaje de la propiedad a los nuevos propósitos, fero tropezaron con los límites de una estrategia que trataba de concebir los beneficios sociales según el modelo de la ciudadanía civil. Tal estrategia estaba necesariamente cargada de tensiones, puesto que la ciudadanía civil se basa en la oposición radical entre donación e intercambio, dependencia e independencia, mientras la ciudadanía social apunta, más allá de estas oposiciones, a la solidaridad e interdependencia.

El reciente intento de los neoconservadores estadounidenses de asimilar los «beneficios sociales» al "contrato» está más en línea con la lógica profunda de aquellas oposiciones. Su estrategia se anuncia en el influyente libro de Lawrence Mead Beyond Entitlement: The Social Obligations of Citizenship (Más allá del derecho: las obligaciones sociales de la ciudadanía), publicado en 1986. Mead defiende que la ciudadanía es un estatus que tiene dos caras; no sólo confiere derechos, sino también implica responsabilidades. Se propone corregir el énfasis unidireccional sobre los derechos sociales que se atribuye a los políticos de izquierda, introduciendo contratos en los que los demandantes de beneficios sociales deben "acordar" que aceptarán el trabajo, la formación y/u otras obligaciones a cambio del subsidio que se les otorga; entrando, así, en la esfera del intercambio. Sin embargo, se olvida de explicar en qué sentido podría ser la transacción propuesta un contrato válido - un acuerdo voluntario y libre entre individuos independientes - cuando una parte carece de los más elementales medios de subsistencia y la otra es el gobierno de los Estados Unidos.

La vigencia de argumentos como el de Mead muestra que las normas contractuales siguen constituyendo hoy un impedimento para los derechos sociales. Se defiende que, al igual que el salario se configura como lo que se obtiene a cambio del trabajo, todos los recursos deberían asignarse en términos de intercambio. El temor a que los receptores de «bienestar" estén "obteniendo algo por nada" se ha convertido en la extendida y comprensiblemente resentida respuesta de quienes trabajan mucho para conseguir poco; los bajos salarios son lo normal, y los trabajadores se sienten más defraudados por los receptores de subsidios que por sus propios patrones. Estas respuestas se radicalizan cuando el pobre está representado como racialmente "otro». El resultado es que, con el miedo a la amenaza 
de una gran depresión, las demandas de los pobres se ven debilitadas hoy en los Estados Unidos a través de una nueva articulación del discurso del contrato.

En suma, la mitología cultural de la ciudadanía civil está en una relación tensa, a veces contradictoria, con la ciudadanía social. Esto no es en ningún lugar más cierto que en los Estados Unidos, donde la ciudadanía civil sigue en gran medida configurada por las nociones de «contrato» e «independencia», mientras el beneficio social se ha construido de modo que remite a la "caridad" y la "dependencia". Lo que echamos de menos es un lenguaje público capaz de expresar ideas que escapen a estas oposiciones dicotómicas: especialmente ideas como solidaridad, reciprocidad no contractual e interdependencia, que son fundamentales para la construcción de una ciudadanía social humana.

Nuestro análisis revela una gran tensión entre la mitología cultural de la ciudadanía civil y la concepción de la ciudadanía sócial de T.H. Marshall. Está claro que los principales obstáculos que encuentra la ciudadanía social en los Estados Unidos son políticos y económicos -tanto internacionales como internos: No obstante, los conceptos ideológicos como «contraton hacen más difícil que crezca el respaldo público a un estado del bienestar, especialmente allí donde la mitología cultural de la ciudadanía civil está más desarrollada. Marshall subestimó estas dificultades ideológicas.

¿Deberíamos, entonces, concluir que la ciudadanía civil y la social son incompatibles? Nuestro análisis no respalda esta conclusión. Por el contrario, mantenemos que la reconciliación de las dos formas de ciudadanía representa una tarea urgente para los teóricos. Comenzaríamos por distinguir aquellos aspectos de la ciudadanía civil basados en la propiedad, antisolidarios, de aquellos otros que no producen necesariamente identificaciones individualistas-posesivas. Pensamos, por supuesto, en la distinción entre los derechos a la propiedad privada de los medios de producción, por un lado, y las libertades civiles tales como la libertad de expresión, por otro. Sospechamos que el aspecto de la ciudadanía civil que crea los mayores obstáculos para la construcción de la ciudadanía social es el relacionado con la propiedad. En un momento de creciente pobreza y desigualdad, y de creciente oposición al estado del bienestar, hay buenas razones para intentar reconstruir una comprensión de las libertades civiles que promueva la ciudadanía social, en vez de impedirla. 


\section{NOTAS}

1. T.H. Marshall: "Citizenship and Social Class", 1949, p. 78.

2. Ibid, p. 113.

3. En este ensayo, usamos "ciudadanía social" para referimos a la concepción de un uestado del bienestar» ideal, propuesta por Marshall y otros; donde nos referimos al bienestar actualmente existente, hablamos de "ayuda socialn, «bienes sociales» o términos similares.

4. C.B. Macpherson: The Political Theory of Possessive Individualism: Hobbes to Locke, Oxford, Oxford U.P., 1974. (Trad esp.: La teoria politica del individualismo posesivo: de Hobbes a Locke, Barcelona, Fontanella, 1979.)

5. Rogers M. Smith: "One United People» (1989).

6. Como acertadamente ha puesto de relieve Judith Shklar.

7. Hoy se mantiene esa misma crítica de los derechos a la intimidad por autoras como Mackinnon. Sin embargo, muchos derechos funcionales de la mujer nacieron como medios de protección de la propiedad de sus señores; este fue el caso, por ejemplo, de las leyes contra la violación (extraconyugal).

8. Por lo menos, esta era la situación en teoría. En la práctica, muy pocos hombres ganaban por sí solos un salario suficiente para mantener a una mujer e hijos dependientes -así, el trabajo, pagado o no, de la mujer y los hijos era crucial para la economía familiar. Es muy necesaria una investigación histórica para determinar el preciso impacto de la protección legal y del mercado de trabajo individual sobre las relaciones familiares de las mujeres y las redes de redistribución de la comunidad.

9. Linda Nicholson: Gender and History: The Limits of Social Theory in the Age of the Family, Nueva York, Columbia U.P., 1986.

10. Desarrollamos este tema en nuestro próximo libro Keywords of the Welfare State.

11. Vid Ios ensayos contenidos en Linda Nicholson (ed.): Women, the State and Welfare, Wisconsin, Wisconsin U.P., 1991, especialmente los articulos de Barbara J. Nelson y Diana Pearce.

12. La hegemonia del trabajo asalariado como base de la utitularidad s es muy importante en esta construcción, y en toda la oposición entre contrato y caridad. Tal privilegio es una ironía, ya que la idea de que el "contrato de trabajo» es un acuerdo libre entre individuos independientes es una mistificación. Sin embargo, tal ficción fundamenta la presunción de que los beneficiarios del seguro social son contratantes independientes y, por tanto, ciudadanos completos de la sociedad civil. Vid. «Contribución, en Fraser y Gordon: Keywords of the Welfare State (próxima publicación).

13. Algunos defensores de los programas estatales de kayuda a las madres» de principios de siglo (precursores de la AFHD) justificaban estos programas como una compensación a la maternidad, que presentaban como un servicio valioso para la sociedad, comparable al que prestaban los soldados. Sin embargo, las ayudas por maternidad, como la AFHD posteriormente, nunca protegieron a la maternidad per se, sino sólo a las madres solteras. Además, la idea de que son una compensación por el servicio a la sociedad nunca se institucionalizó y habia desaparecido en su mayor parte hacia la época en que los programas estatales fueron federalizados por la Ley de Seguridad Social de 1935. Por entonces, el trabajo asalariado llegó a ser tan hegemónico que, junto con el servicio militar, eran las únicas bases para el derecho a cualquier beneficio social que fuera más allá de las más elementales necesidades. Vid el artículo de Ann Orloff y Theda Skocpol: «Protecting Mothers and Soldiers" (Harvard U.P., próxima publicación).

14. Adernás, hay un tercer nivel del estado previsor, no siempre visible para el observador no avisado, que desafía la dicotomía. Se trata del campo de los salarios complementarios en especic y los planes de pensiones y seguro disponibles en el mercado para los trabajadores sindicados, las clases medias y los ricos. Normalmente considerados «privados" y, por tanto, la quintaesencia del contrato, frente a la caridad, esta forma de previsión disfruta de exenciones impositivas que equivalen a un gran subsidio del gobierno que podría ser considerado incluso 
como una «limosna». Sin embargo, aparece como legitima por su relación con el trabajo asalariado, que es la forma fundamental de "contribución» en una sociedad capitalista dominada por hombres.

15. Reich: "The New Property" y «Beyond the New Property". Sparer, de la Brooklyn Law Review en el aniversario del caso Goldberg Vs. Kelly (en especial el articulo de Sylvia Law). Opinión mayoritaria del Tribunal Supremo en el caso Goldberg Vs. Kelly.

16. Sparer ofrece la explicación más lúcida y políticamente más astuta de los logros y limitaciones de las estrategias legales que se siguieron en los últimos sesenta y comienzos de los setenta. Reich y Simon describen la eliminación parcial de las garantias procesales a través de las decisiones judiciales de los años setenta y ochenta. 